\title{
Identificação de metáforas em uma obra terminográfica: definição de critérios e análise de $\operatorname{casos}^{1}$
}

\author{
Maity Siqueira \\ Ana Flávia Souto de Oliveira \\ Dalby Dienstbach Hubert \\ Galeno Faéde Almeida \\ Larissa Moreira Brangel
}

Resumo: This paper demonstrates that metaphor is not simply a literary device, but a part of technical linguistic environments. The Theory of Conceptual Metaphor suggests that our conceptual system is fundamentally metaphorical. Concepts arise from our everyday interaction with the world and semantic structure reflects the conceptual structure. Metaphor, therefore, is pervasive in everyday life, not just in language but in thought and action. Based on these assumptions, we analyzed a terminological dictionary to find metaphorically used lexical items. We then tried to determine the most literal meaning of each item in other contexts. In order to do so, the procedures we developed were complemented by a method for identifying metaphorically used items elaborated by the Pragglejaz Group. The results confirm the pervasiveness of metaphor and show how polysemy is motivated. Moreover, there seems to be no clear boundaries between literal and figurative language.

Palavras-chave: Semântica Cognitiva; Metáfora Conceitual; Metáfora Primária; Terminologia; Dicionário Terminológico.

\section{Introdução}

A metáfora tem alimentado discussões acadêmicas há pelo menos 2.000 anos e, durante quase todo esse tempo, foi vista como um adorno da linguagem.

\footnotetext{
'Este artigo é parte do projeto de pesquisa "Metáfora em Obras de Direito Ambiental", desenvolvido na Universidade Federal do Rio Grande do Sul, sob coordenação da Profa. Dr. Maity Siqueira.
} 
Atualmente, essa é considerada a visão clássica, segundo a qual as metáforas são um tipo de adição à linguagem ordinária, utilizadas estilisticamente para obter um efeito diferenciado.

Nas últimas décadas, o fenômeno da metáfora tem conquistado um lugar de destaque, principalmente nos trabalhos de lingüistas e filósofos, e também tem sido objeto de interesse de estudiosos das ciências do léxico e de suas interfaces.

Dentre as ciências do léxico, a Terminologia, que se oçupa das linguagens de especialidade, surgiu como uma disciplina prescritiva, opondo-se aos estudos científicos da linguagem, e só aos poucos foi se colocando em uma relação de complementaridade com a Lingüística.

Nesse primeiro momento, a idéia de um texto especializado conter termos ou definiçốes terminológicas polissêmicos não era bem-vinda. Na linguagem técnicocientífica, objetividade e clareza eram vistos como elementos fundamentais, devido à necessidade de precisão das informações. Assim, palavras de sentido vago, ambíguo ou figurado não deveriam, na perspectiva da Terminologia tradicional, estar relacionadas a esse ambiente.

Segundo Temmerman (2000), a crença objetivista das abordagens terminológicas tradicionais trata a metáfora como um elemento indesejado e pertencente à linguagem figurada, devendo ser, portanto, substituída por um equivalente literal (TEMMERMAN, 2000, p. 158). No entanto, a autora defende a necessidade de uma nova abordagem na Terminologia e diz que a pesquisa das metáforas na linguagem especializada possui relevância para essa disciplina. Um de seus postulados é que a metáfora é um fenômeno de importância fundamental para os processos de lexicalização.

Entre as pesquisas mais recentes em Terminologia (CABRÉ, 1998; TEMMERMAN, 2000; WEISSENHOFER, 1995; FINATTO, 2001), já é consenso a idéia de que esse é um campo de estudo que deve ampliar seu escopo, de modo a englobar a diversidade lingüística em todos os seus aspectos-inclusive o figurado. Todavia, ainda são raras as pesquisas enfocando o tópico "metáfora" em Terminologia (HUANG, 2005; DIAS, 2004; TEMMERMAN, 2000) e não se conhece nenhum trabalho que considere especificamente a Teoria da Metáfora Primária nesse campo de estudo.

O que se pretende, neste artigo, é discutir a possibilidade de ocorrências metafóricas em termos e definições de uma obra terminográfica, mais especificamente o Dicionário de Direito Ambiental (KRIEGER et al., 2 ed., no prelo). Partindo de uma perspectiva descritiva e textual da Terminologia, propóe-se uma interface entre a Teoria das Metáforas Conceituais (LAKOFF e JOHNSON, 1980), que compreende a Teoria das Metáforas Primárias (GRADY, 1997), e a Teoria Sócio-Cognitiva da Terminologia (TEMMERMAN, 2000).

\section{Pressupostos teóricos}

A Teoria da Metáfora Conceitual, perspectiva desenvolvida por Lakoff e Johnson (1980) para tratar do fenômeno da metáfora, é conhecida como "abordagem experiencialista" e está ancorada em duas idéias centrais. A primeira é a de que a metáfora não é um fenômeno lingüístico periférico, mas uma questão cognitiva central, uma vez que a mente humana freqüentemente opera com conceitos que se conectam metaforicamente com outros conceitos de estrutura similar (LAKOFF e JOHNSON, 1980; GIBBS, 1999). A segunda idéia é a de que a razão tem uma base corpórea e experiencial.

Essa abordagem trata as metáforas como uma correspondência sistemática - ou mapeamento - entre dois domínios conceituais: o domínio-fonte, tipicamente mais concreto, estruturado, ou acessível aos sentidos, que serve como fonte de inferências; e o domínio-alvo, tipicamente mais abstrato, menos estruturado, ao qual as inferências se aplicam.

Então, por exemplo, as pessoas têm um conhecimento coerentemente organizado sobre o domínio conceitual TAMANHO, no qual se baseiam para entender o domínio conceitual IMPORTÂNCIA.É esse o mapeamento presente na metáfora conceitual IMPORTÂNCIA É TAMANHO. Nessa metáfora, portanto, TAMANHO é a fonte, e IMPORTÂNCIA é o alvo. As metáforas conceituais tornam-se manifestas através de realizaçōes lingüísticas, chamadas de metáforas lingüísticas. Utilizamos expressões do tipo: "o telefone foi uma das grandes descobertas do século" ao nos referirmos metaforicamente a um evento importante.

Os esquemas de imagem - representações conceptuais relativamente abstratas que se originam diretamente de nossa interação diária com o ambiente e da observação do mundo em que vivemos - podem fornecer a base concreta para esses mapeamentos metafóricos (EVANS e GREEN, 2006). Por serem os primeiros conceitos que surgem na mente humana e por estarem relacionados à experiência sensório-perceptiva, tais esquemas não são ricos em detalhes, mas são conceitos abstratos que resultam de repetidas instâncias da experiência corporificada. Tal experiência, segundo Lakoff e Johnson (1980), dá origem à estrutura conceptual: o sistema cognitivo que representa e organiza a experiência de maneira que possa servir de base à expressão lingüística. Pode-se dizer, assim, que a estrutura semântica reflete a estrutura conceptual e que esta tem origem na experiência corporificada.

\footnotetext{
${ }^{2}$ Mantendo uma convenção estabelecida na área, as metáforas conceituais são apresentadas em caixa alta e as atualizações lingüísticas - derivadas das metáforas conceituais - são apresentadas entre aspas.
}

Organon, Porto Alegre, $n^{\circledR} 43$, julho-dezembro, 2007, p. 181-195 
Os esquemas de imagem não são específicos de apenas um sentido. Apesar de o termo "imagem" na linguagem cotidiana se restringir à percepção visual, em lingüística cognitiva, sua aplicação abrange todos os tipos de experiência sensórioperceptiva. Alguns esquemas de imagem são: recipiente, parte-todo, centroperiferia, ligação, origem-percurso-meta e equilíbrio.

Em consonância com a perspectiva da abordagem experiencialista, Grady (1997) desenvolveu a Teoria das Metáforas Primárias. Grady postula que algumas metáforas conceituais emergem de correlações entre dimensões distintas de experiências corpóreas básicas recorrentes e co-ocorrentes. Um exemplo de metáfora primária é a metáfora conceitual DIFICULDADE É PESO.As pessoas, no seu dia-a-dia, independentemente de sua cultura, experienciam algum grau de dificuldade e de desconforto físico ao tentar carregar um objeto pesado. Invariavelmente, quanto maior o peso do objeto a ser levantado, maior é a dificuldade experienciada. Peso e dificuldade, portanto, são dois domínios experienciais recorrentes e co-ocorrentes, que ilustram um mapeamento conceitual entre um domínio-fonte (PESO) e um domínio-alvo (DIFICULDADE). A partir desse mapeamento, temos atualizações lingüísticas do tipo "hoje a aula foi leve" e "tive um dia pesado no trabalho".

Os mapeamentos metafóricos primários, portanto, derivam de experiências físicas e cognitivas básicas co-ocorrentes e são potencialmente universais. Ou seja, dadas as experiências corpóreas universais nas quais estão baseadas, esperase que essas metáforas possam ocorrer em línguas e culturas diversas no mundo, nos diferentes ambientes lingüísticos.

Por conta do objeto desta pesquisa (um dicionário técnico-científico), utilizamos uma teoria terminológica que parte dos postulados da Semântica Cognitiva: a Teoria Sociocognitiva da Terminologia (TSC). Desenvolvida por Rita Temmerman (2000), a TSC defende que parte do conhecimento científico e tecnológico é apreendido através de nossas percepções sensoriais, como resultado da interação entre a linguagem, a mente, o corpo humano e o mundo.

Um dos pilares da TSC, que também vai ao encontro da proposta experiencialista, é a contestação à idéia de que há uma verdade absoluta e incondicional, que pode ser totalmente descrita através de aspectos denotativos, literais, sob uma perspectiva sincrônica da linguagem. Temmerman, ao invés disso, acredita que a linguagem não pode ser reduzida a um nível consciente e literal, e que análises diacrônicas, muitas vezes, são essenciais para entender o significado de um termo, em um dado momento de uma determinada disciplina.

Fazendo um contrapondo aos princípios norteadores da Teoria Geral da Terminologia (TGT), a TSC propõe que, em relação às unidades de entendimento, tanto a univocidade quanto a polissemia e a sinonímia podem pode ser funcionais e que as expressões figuradas são parte da descrição terminológica.

\section{Materiais e métodos}

O Dicionário de Direito Ambiental (KRIEGER et al., 2 ed., no prelo), doravante DDA, foi escolhido por se tratar de uma obra terminográfica escrita na variedade do português brasileiro e fazer parte do acervo Termisul. ${ }^{3}$

A investigação do dicionário realizou-se pela inspeção manual dos termos, das definições e observações que compõem a obra. Com base nos fundamentos da Teoria das Metáforas Conceituais (LAKOFF e JOHNSON, 1980), essa investigação se ocupou da identificação e descrição das metáforas lingüísticas e conceituais no referido corpus.

Os resultados das buscas por ocorrências metafóricas no dicionário, desempenhadas por cada integrante do grupo de pesquisa, foram discutidos coletivamente. Porém, a imprecisão e não-circunscrição das metáforas, a subjetividade na avaliação do que seja, de fato, metafórico e a falta de parâmetros estabelecidos por pesquisadores que se apliquem à identificação de metáforas (conceituais e lingüísticas) muitas vezes tornaram complexas as decisões a serem tomadas pelo grupo. Em função disso, a pesquisa envolveu também a elaboração e aplicação sistemática de critérios que favoreceram uma identificação mais objetiva e clara das atualizações metafóricas no dicionário analisado.

Inicialmente, a análise das ocorrências metafóricas no dicionário tomou como base o Procedimento de Identificação de Metáforas-PIM (PRAGGLEJAZ GROUP, 2007). Esse procedimento sistematiza um conjunto de métodos que refletem, em certa medida, o processo de identificação de metáforas lingüísticas que vinha sendo realizado pelo grupo de pesquisa. Desse modo, a identificação de metáforas envolveu:

1. Leitura dos termos, definições e observações do dicionário;

2. Identificação dos itens lexicais potencialmente metafóricos;

3. (a) Determinação do seu significado no contexto (significado contextual);

(b) Busca por um significado mais básico do item lexical;

(c) Comparação dos significados contextual e mais básico desses itens e decisão quanto a sua eventual oposição;

4. No caso de oposição, marcação do item lexical como metafórico.

Para os nossos propósitos, significados mais básicos são aqueles sugeridos pelo grupo Pragglejaz: mais concretos (mais acessíveis aos sentidos), relacionados ao

${ }^{3}$ Grupo de pesquisa responsável pelo Projeto Terminológico Cone Sul, originado no Instituto de Letras da Universidade Federal do Rio Grande do Sul, em Porto Alegre, acessível no site $<$ http://www6.ufrgs.br/termisul/>.

Organon, Porto Alegre, $n^{2} 43$, julho-dezembro, 2007, p. 181-195 
funcionamento do corpo (motivados pelo aparato sensório-motor humano), mais precisos (cognitivamente mais estruturados) e historicamente mais antigos.

Com a intenção de precisar a determinação dos significados dos itens lexicais, recorremos a dois dicionários brasileiros contemporâneos: Novo Dicionário Aurélio e Dicionário Eletrônico Houaiss. O segundo foi mais utilizado por incluir informaçōes etimológicas dos verbetes e permitir, portanto, a identificação do significado historicamente mais antigo dos itens lexicais.

A aplicação do PIM será demonstrada a partir da definição do termo energia fóssil, retirada do DDA: "Energia gerada pela combustão de depósitos de restos de material orgânico, com alto teor de carbono e hidrogênio, preservado em estado fóssil na crosta terrestre, tais como carvão, petróleo, gás natural".

Atentamos para o item lexical alto e seu significado nesse contexto: "adj. 7 fig. muito grave, sério; excessivo" (HOUAISS, 2001). Sugerem-se como significados mais básicos desse item as acepções: " $a d j$. 1 de grande dimensão vertical; de altura superior à média; elevado 2 consideravelmente acima do solo; que está ou sobe a grande distância da superfície terrestre 3 muito acima da linha do horizonte" (HOUAISS, 2001).

Ao compararmos esses significados de alto, verificamos que o significado contextual contrasta com os mais básicos, ainda que possa ser compreendido em relação a eles. Com efeito, pode-se entender um acréscimo ou aumento abstrato do teor de carbono em termos de um aumento ou, mais precisamente, de uma elevação física do nível de uma substância líquida em um copo, por exemplo. Nesse caso, então, o item lexical alto é identificado como metafórico.

A preocupação do grupo de pesquisa em elaborar uma combinação de critérios que auxiliassem na análise e descrição das respectivas metáforas resultou na formulacão de dois outros critérios, além dos já citados: um voltado para a produtividade da metáfora conceitual e outro voltado para uma possível resistência da metáfora lingüística a uma paráfrase literal.

No que diz respeito à produtividade de uma metáfora conceitual, buscamos determinar se, a partir dela, ocorrem outras expressões lingüísticas metafóricas afora aquela já identificada. Exclui-se, nesse caso, a necessidade de se fazer uso do mesmo item lexical. Em outras palavras, não é a recorrência do item lexical metafórico de uma atualização lingüística que vai representar a produtividade da sua metáfora conceitual, mas sim as atualizações lingüísticas metafóricas em si.

É possível se valer da produtividade de uma metáfora para indicar o grau, maior ou menor, de metaforicidade da sua atualização lingüística. Além disso, a produtividade pode servir como um fator representativo da recorrência de uma metáfora conceitual dentro dos diversos contextos que compõem o corpus, que, nesse caso, são os termos, as definições e observações do dicionário.
Ainda com relação ao item lexical alto, na definição de energia fóssil, tem-se a metáfora conceitual MAIS É PARA CIMA. Essa metáfora conceitual é bastante produtiva, pois é atualizada em diversas expressões lingüísticas no próprio DDA:

I) energia renovável cuja utilização oferece alto risco de acidentes.

II) poluentes orgânicos persistentes altamente tóxicos .

III) conjunto de medidas legais, técnicas e administrativas que visam a reduzir a exposição de seres vivos à radiação ionizante a níveis tão baixos quanto razoavelmente exeqüível.

Logo, pode-se verificar o potencial de produtividade da metáfora conceitual MAIS É PARA CIMA e concluir que o grau de metaforicidade dessas atualizações lingüísticas é bastante alto.

Como último critério, buscou-se determinar se há pelo menos uma paráfrase da metáfora lingüística em questão que se realize com um item lexical sinônimo de significado mais básico. Nesse sentido, considera-se a paráfrase literal cujo resultado apresenta o mínimo de prejuízo de sentido possível em relação à metáfora lingüística.

No excerto, extraído do DDA, "energia renovável cuja utilização oferece alto risco de acidentes", por exemplo, pode-se sugerir "risco excessivo", sem alterar significativamente o sentido da atualização lingüística.

No caso de o contexto investigado inviabilizar uma paráfrase literal da metáfora lingüística, ou seja, se a tentativa de apelarmos a um item lexical mais básico implicar a perda significativa do sentido da frase, então está evidenciada a inescapabilidade dessa metáfora. Com isso, admite-se que o significado contextual do item lexical investigado seja o único possível nesse ambiente.

No exemplo do DDA "produto imediato do cruzamento entre linhagens geneticamente diferentes", uma paráfrase literal é insatisfatória. Ao ser comparado o significado de cruzamento nesse contexto, "acasalamento entre organismos distintos morfológica ou geneticamente" (HOUAISS), com os seus significados mais básicos, "posição ou disposição em forma de cruz" e "ponto de interseção entre coisas que se cruzam" (HOUAISS), pode-se tomá-lo por metafórico. No entanto, não haveria, em princípio, algum item lexical que equivalesse a sua carga semântica, e o seu significado mais particular enfraqueceria nesse contexto. Cruzamento, nesse caso, foi considerado um exemplo de polissemia, com evidente origem metafórica.

A partir da aplicação dessa combinação de critérios, as ocorrências identificadas e analisadas pelo grupo de pesquisa foram divididas em casos metafóricos prototípicos e não-prototípicos. 


\section{Análise dos dados}

\subsection{Casos prototípicos}

Foram considerados casos prototipicamente metafóricos aqueles em que foi possível determinar satisfatoriamente uma diferença entre um uso metafórico (mais abstrato) do item lexical no contexto apresentado pelo DDA e um uso literal (mais concreto ou mais básico). Para determinar o que seria seu uso mais literal, recorreu-se ao auxílio dos dois dicionários mencionados. Após determinar os usos distintos do item lexical, o passo seguinte foi identificar a metáfora conceitual e as correlações estruturais que possibilitariam tais atualizações lingüísticas.

Analisaremos aqui alguns dos casos identificados como prototípicos, relacionados no quadro abaixo.

\begin{tabular}{|c|c|}
\hline Uso literal & Uso metafórico \\
\hline lagos existentes dentro do território & lavagem dentro de 24 horas \\
\hline através da seção transversal de um escoamento & através de profundas mudanças estruturais na sociedade \\
\hline rede composta de três malhas justapostas & rede de assistência técnica autorizada \\
\hline
\end{tabular}

Quadro 1: Casos prototípicos

\subsubsection{Dentro}

No caso do item lexical dentro, considerou-se que seu uso no contexto da seguinte frase do DDA seria claramente literal: "Mares, rios e lagos existentes dentro do território de um Estado, pertencentes à sua jurisdição". Nesse caso, o sentido do item lexical estaria mais próximo do que se considerou ser o modelo cognitivo que idealmente define dentro. Esse modelo poderia incluir ainda um componente vertical de tridimensionalidade, como em "dentro de uma caixa" ou "dentro de casa"; entretanto, entendeu-se que o plano bidimensional seria suficiente para indicar nesse exemplo seu caráter literal. Pode-se dizer, nesse caso, que o modelo cognitivo que define dentro é o esquema do recipiente (ou contêiner).

O próximo exemplo do DDA, por outro lado, foi considerado metafórico: "sem posterior lavagem dentro de 24 horas e após observação subseqüente por 7 dias". Nesse caso, entendeu-se que o item lexical estava sendo utilizado em um contexto diferente daquele considerado literal, pois tomava o período das 24 horas que formam um dia como sendo um recipiente.

Além dos exemplos de sentido mais literal da primeira frase e mais metafórico da segunda, o modelo de recipiente também funciona de modo semelhante nos exemplos abaixo, ordenados segundo um nível crescente de abstração:
I) camada gasosa, situada dentro da atmosfera, que absorve os raios solares. II) propagação de vibrações mecânicas [...], dentro da faixa de freqüência de $16 \mathrm{~Hz}$. III) troca de materiais entre as partes vivas e não vivas claramente definidos dentro do sistema.

IV) que explore [...] imóvel rural, dentro de condição de rendimento econômico.

O esquema do recipiente se aplica, respectivamente, com relação: I) à camada gasosa definida como atmosfera; II) ao "espaço" da faixa de freqüência de $16 \mathrm{~Hz}$; III) ao que se entende como sendo o sistema; IV) ao conjunto das condições de rendimento econômico.

Pode-se dizer que a percepção de correlaçôes estruturais similares entre os diferentes domínios é uma das hipóteses que melhor explica essas variações de sentido. Um domínio mais abstrato é compreendido por meio de um domínio mais concreto, ou seja, estruturas conceituais mais simples são mapeadas para estruturar conceitos mais complexos. A percepção dessas estruturas correlacionais não parece depender da etimologia do item lexical, pois o esquema do recipiente com semelhantes correlações pode ser observado em todas elas.

No exemplo "sem posterior lavagem dentro de 24 horas", o esquema do recipiente combina-se ainda com a metáfora conceitual segundo a qual TEMPO É ESPAÇO, isto é, o domínio abstrato do tempo costuma ser entendido através do domínio concreto do espaço. A medição de um espaço físico pode ser diretamente experimentada, enquanto que medir o tempo é algo mais dificilmente acessível aos sentidos e que geralmente fazemos apenas artificialmente, com o auxílio de recursos como o relógio.

Esses exemplos atestam que o domínio-fonte do ESPAÇO é altamente produtivo para expressar o domínio-alvo do TEMPO, como fica evidenciado nas inúmeras realizações lingüísticas cotidianas que se valem de relações espaciais para expressar relações temporais, como nos exemplos que seguem: "estamos longe do inverno", “o Natal já está próximo”, “chegou a hora de mudar”," passamos da hora" e "encurtaram nosso prazo".

\subsubsection{Através}

Com relação ao item lexical através, os diferentes sentidos resultam de correlações estruturais baseadas no esquema origem-percurso-meta (O-P-M), que possibilita a estruturação de um domínio mais abstrato em termos de outro mais concreto. O sentido do primeiro exemplo, extraído do DDA, foi considerado literal, enquanto que o do segundo foi considerado metafórico:

I) volume de fluido que passa por unidade de tempo, através da seção transversal de um escoamento.

Organon, Porto Alegre, nº 43, julho-dezembro, 2007, p. 181-195 
II) baseia-se na idéia de que o homem só poderá integrar-se perfeitamente na biosfera através de profundas mudanças estruturais na sociedade industrial moderna.

$\mathrm{Na}$ frase I, o fluido parte do local O por meio da seção transversal $\mathrm{P}$ e chega ao local M. De modo análogo, na frase II, o homem em uma situação $O$, por meio de profundas mudanças estruturais na sociedade industrial moderna $\mathrm{P}$, chega à situação $\mathrm{M}$.

Entre o uso mais concreto em I e o mais abstrato em II, podem-se observar diversos estágios intermediários em que o nível de abstração pode ser considerado crescente, como nos excertos abaixo. Em III, por exemplo, a substância em questão percorre um trajeto físico nos tecidos lenhosos, e em IV a própria sucessão de geraçōes parece formar o caminho a ser percorrido.

III) alta difusibilidade através dos tecidos lenhosos.

IV) mantenha a sua homogeneidade através de gerações sucessivas.

V) outros organismos colocados em seu genoma através de técnicas de ADN recombinante.

VI) instrumento internacional bilateral, através do qual um país industrializado. VII) objetiva uma melhor qualidade de vida através da transformação da sociedade industrial.

\subsubsection{Rede}

Nos exemplos do item lexical rede, a imagem visual de uma rede de pescar com seus pontos de interconexão é correlacionada a um conceito abstrato que se faz de outros sistemas cujo funcionamento também é compreendido através de nódulos interconectados. Nos excertos abaixo, essa metaforização ocorre de forma gradual a partir de correlações mais físicas e concretas, como no caso de uma rede viária ou telefônica, em que tanto as estradas quanto os cabos e suas conexões são visíveis, até uma correlação mais abstrata, como na rede varejista, em que essas semelhanças estruturais não são observáveis ou não existem fisicamente.

I) petrecho de pesca constituído por rede composta de três malhas justapostas. II) por suas características peculiares, não podem ser lançados na rede de esgoto. III) desde que atendidos os seguintes requisitos: aproveitamento da rede viária existente.

IV) coletas de águas pluviais, rede telefônica e gás canalizado.

V) atividade de comercialização por atacado com a rede varejista.
Percebe-se assim que as várias acepç̃es do item lexical estão ligadas por uma "cadeia de sentidos". Além disso, pode-se dizer que a correlação entre os diversos sentidos é tanto gradual quanto subjetiva. A polissemia de itens lexicais como dentro, através e rede, entre outros, não seria, portanto, arbitrária, mas altamente motivada.

\subsection{Casos não-prototípicos}

Foram consideradas como não-prototípicas aquelas ocorrências em que não foi possível determinar satisfatoriamente um sentido literal em outro contexto e cujas possíveis extensões metafóricas pareceram depender, no mínimo, de considerações de natureza diacrônica ou etimológica. Aponta-se, nestes casos, para uma evidente origem metafórica.

As ocorrências consideradas não-prototípicas que analisaremos a seguir são os itens lexicais lesão, centro, banco e visar.

\subsubsection{Lesão}

A indeterminação no caso de lesar se relaciona ao fato de o item aparentemente ter um sentido mais primário de um ferimento ou contusão física (é também a primeira acepção que aparece nos dois dicionários consultados). Este sentido mais físico parece se estender por meio de processos metafóricos ou metonímicos, através da personificação do ambiente e dos direitos, para se referir a estes domínios como se fossem um ser vivo. No DDA, em duas de suas ocorrências, o item lexical lesão aparece na definição da entrada Dano, em que a "entidade" ou "paciente" afetados são um bem e o meio-ambiente. Em outras duas, a "entidade" lesada é o interesse difuso ("uma lesão ao interesse difuso violado") ou o direito ("prevenir qualquer lesão de direito").

Apesar de parecer que este sentido mais físico tenha sido realmente estendido, via metáfora ou metonímia, para se referir a domínios mais abstratos - como os direitos ou o ambiente (entendidos como seres vivos) - essa correlação não ficou evidenciada de modo satisfatório.

\subsubsection{Centro}

Outro item lexical não-prototípico (que não segue o padrão do que o grupo considerou como tipicamente metafórico) foi a do item centro, como nos exemplos a seguir: 
I) rede circular, de malha fina, com pesos na periferia e um cabo fino no centro, pelo qual é puxada.

II) as espécies citadas acima ocorrem no Centro e Norte do país.

III) lotes de colonização que se destinam a constituir o centro da comunidade incluindo as residências dos trabalhadores dos vários serviços.

IV) o ambiente é mantido o mais próximo do natural, devendo conter centro de visitantes, museus, outras facilidades e serviços.

O item lexical centro (central) pode ser empregado de modo totalmente literal, como em: "mire no centro daquele círculo", "o vaso foi colocado no centro da mesa" e "nosso terreno tem uma localização bastante central”. Porém, também pode ser empregado de modo mais abstrato, isto é, sem referência a um centro físico ou espacial. O esquema que funciona nestes casos é o de centro-periferia, sendo o que é central mais importante em relação ao que é periférico. Essas correlações possibilitam a metáfora conceitual IMPORTANTE É CENTRAL, que é realizada lingüisticamente em expressões como: "Ela pensa que é o centro das atenções" "Questões periféricas devem ser deixadas de lado até que se resolva o problema central" e "No centro da disputa pelas terras estão as jazidas de diamantes".

Além desses exemplos, o item lexical centro ocorre também, freqüentemente, em combinações como: centro de visitantes, centro de estudos, centro de saúde e centro comunitário. Nesses casos, mais do que à idéia de centralidade, o item parece se referir a um espaço físico específico que é um local de convergência de interesses ou atividades afins. Esse sentido parece se manter mesmo quando não se pode delimitar um espaço físico definido, como em: "Aquela região é um centro de distribuição de drogas" e "Porto Alegre tornou-se um centro de produção cinematográfica".

Nos casos em que centro aparece em combinações, pode-se distinguir novamente um uso mais literal (centro de saúde) de um mais abstrato (centro de produção). Parece que, nestes casos, o item centro, já derivado metaforicamente, consolida outro núcleo de sentido mais literal que pode novamente ser expandido de forma metafórica.

\subsubsection{Banco}

$\mathrm{O}$ item lexical banco também foi considerado não-prototípico devido a peculiaridades em sua possível extensão metafórica. A primeira questão a considerar com relação a este item diz respeito a sua caracterização como um caso de homonímia ou de polissemia. O Aurélio trata o item como um caso de homonímia, colocando-o em duas entradas separadas: uma para o banco de sentar e outra para a instituição financeira. Já o Houaiss apresenta o item como um caso de polissemia, dando-lhe uma única entrada com diversas acepções. Independentemente de uma possível origem comum para os sentidos de banco e banco , se considerarmos apenas o sentido de banco ${ }^{2}$ (instituição financeira), temos uma situação semelhante à apresentada com relação ao item centro.

O sentido de banco ${ }^{2}$ (instituição financeira) é estendido gradativamente para se referir a locais em que, de modo mais concreto ou mais abstrato, se "armazenam" outros tipos de entidades: Banco Nacional de Desenvolvimento, banco de germoplasma, banco de dados, banco de talentos e banco de idéias.

\subsubsection{Visar}

Outro exemplo de ocorrência metafórica considerada não-prototípica é a do item visar. Entre as ocorrências encontradas no DDA, temos:

I) caçador que visa fim exclusivamente esportivo.

II) produção visando seu plano de abastecimento.

III) ação visando recompor área.

IV) visando ao bem da coletividade.

Em todos esses casos, o item visar significa objetivar. Há, porém, um uso mais literal do mesmo item com o sentido de mirar, como em: Ele visou o alvo e atirou. Ou ainda mais literal, como em: "Sentada no sofá, ela visava os objetos na sala".

A questão que se coloca aqui é que, apesar de ser possível separar um sentido mais literal (mirar/olhar) e outro mais metafórico (objetivar) para o mesmo item lexical, o sentido de mirar é usado raramente, enquanto o de olhar está praticamente em desuso. Portanto, uma possível "origem metafórica" dependeria, nesse caso, de considerações de natureza etimológica e diacrônica.

Poder-se-ia argumentar, então, que visar teria hoje apenas o sentido de objetivar, que já estaria cristalizado na língua, não sendo, portanto, uma metáfora. $\hat{\mathrm{E}}$ a isso que, tradicionalmente, se denominaria metáfora morta (LAKOFF e JOHNSON, 1980).

O verbo visar, porém, apesar de raramente usado com o sentido de mirar/ olhar, ainda traz esse registro abonado nos dicionários. Além disso, há casos bastante freqüentes na língua em que os diversos sentidos do item lexical parecem co-ocorrer, como em: "Aquela casa era muito visada", "Seu carro não podia ser visto lá", "Muitas pessoas são visadas devido a suas origens étnicas", "Ele estava visado naquela cidade, teria de aplicar seus golpes em outro lugar".

O DDA traz ainda diferentes usos do item lexical também com o sentido de objetivar: I) com vista a maior comodidade e II) tendo em vista o atendimento. E outros usos gerados a partir de diferentes extensões de sentido, como em: "é 
necessário visar este cheque" (dar o visto) e "meu visto de entrada nos EUA fo negado mais uma vez".

Tendo em vista a extrema produtividade do verbo ver, atestada por uma infinidade de expressões que usam o sentido físico da visão para conceitualizar outros domínios, fica difícil argumentar que esta seria uma metáfora morta. Todas essas extensões de sentido são possíveis devido às maneiras que entendemos o ato de ver, a partir das quais se originam metáforas conceituais como OBJETIVAR É VER, CONHECER É VER, SABER É VER, entre outras. O verbo ver, portanto, considerando-se uma perspectiva diacrônica que parece indispensável, apesar de menos prototípico, mostra-se bastante produtivo metaforicamente.

\section{Conclusão}

Por não haver na literatura critérios pré-estabelecidos para a identificação de metáforas, foi necessário que o grupo desen volvesse seus próprios critérios. As discussões, no princípio, concentravam-se sobretudo em determinar para cada item lexical o que seria um sentido mais literal ou mais metafórico.

Com a aplicação dos critérios sugeridos pelo grupo Pregglejaz, complementados pelos critérios elaborados pelo grupo de pesquisa, o processo de identificação passou a ser mais claro e objetivo. Mesmo assim, constatou-se que um certo grau de subjetividade parece estar sempre presente na investigação das metáforas.

De acordo com a avaliação do grupo, as ocorrências metafóricas foram divididas entre casos prototípicos, com uma delimitação entre sentido literal e metafórico, e não-prototípicos, em que esta delimitação foi menos categórica. Apesar disso, a classificação entre os diferentes grupos de itens lexicais foi principalmente operacional, pois não há entre eles uma fronteira claramente delimitada.

Além disso, para cada item lexical, apesar de ser possível diferenciar seus usos literais de seus usos metafóricos, verificou-se que entre esses dois extremos existe um continuum de sentido, sendo que um ou mais sentidos concretos podem ser considerados mais centrais ou prototípicos de uma família de sentidos relacionados.

Corroborando a hipótese inicial deste trabalho, verificou-se que, por serem inerentes à linguagem, as metáforas conceituais ocorrem de modo inescapável e disseminado nesta obra terminográfica. Além disso, pode-se dizer que as extensões metafóricas estão entre os principais motivos da polissemia dos itens lexicais.

\section{Bibliografia}

CABRÉ, Maria Tereza. Elementos para una teoria de la terminologia: hacia um paradigma alternativo. El Lenguaraz, Ano 1, n.1, p.59-77, abril de 1998.

DIAS, James G. Terminologia: a função da metáfora na formação dos termos. Tese (Doutorado) - USP, São Paulo, 2004.

EVANS, Vyvyan; GREEN, Melanie. Cognitive Linguistics: an introduction. New Jersey/London: Lawrence Erlbaum Associates Publishers, 2006.

FERREIRA, Aurélio Buarque de Holanda. Novo Dicionário Aurélio da Língua Portuguesa. 3 ed. Curitiba: Positivo, 2004.

FINATTO, Maria José B. Definição terminológica: fundamentos teóricometodológicos para sua descrição e explicação. Tese (Doutorado) - Universidade Federal do Rio Grande do Sul, Porto Alegre, RS, 2001.

GIBBS, Jr. Raymond W. Taking metaphor out of our heads and putting it into the cultural world. In: GIBBS, R.; STEEN, G. Metaphor in Cognitive Linguistics. Amsterdam: John Benjamins, 1999.

HOUAISS, Antônio. Dicionário Eletrônico Houaiss da Língua Portuguesa. Versão 1.0. Rio de Janeiro: Objetiva, 2001.CD-Rom.

HUANG, Carolina. A metáfora no texto científico de medicina: um estudo terminológico da linguagem sobre AIDS, 2005.Dissertação (Mestrado) - Universidade Federal do Rio Grande do Sul, Porto Alegre, 2005.

KÖVECSES, Zoltan. Metaphor: a practical introduction. New York: Oxford University press, 2002.

KRIEGER, Maria da Graça; MACIEL, Anna Maria B.; ROCHA, J. C. C.; FINATTO, Maria José B.; BEVILACQUA, Cleci R. Dicionário de Direito Ambiental: Terminologia das leis do meio ambiente. (no prelo).

LAKOFF, George; JOHNSON, Mark. Metaphors we live by. Chicago: University of Chicago Press, 1980.

LAKOFF, George. Women, fire, and dangerous things: what categories reveal about the mind. Chicago: University of Chicago Press, 1987.

PREGGLEJAZ GROUP. MIP: a method for identifying metaphorically used words in discourse. Metaphor and symbol, Santa Cruz (US), v.22, n.1, p.1-39, 2007.

TEMMERMAN, Rita. Towards new ways of Terminology Description: the sociocognitive approach. Amsterdam/Philadelphia: John Benjamins, 2000.

WEISSENHOFFER, Peter. Conceptology in terminology theory: semantics and word-formation. Wien: TermNet, 1995.

YU, Ning. The Contemporary Theory of Metaphor. Philadelphia: John Benjamins, 1998. 